\title{
Experimental Validation of a Mixed-Lubrication Regime Model for Textured Piston- Ring-Liner Contacts
}

\author{
Francisco J. Profito $^{\mathrm{a}, \mathrm{b}}$, Sorin-Cristian Vladescu ${ }^{\mathrm{b}}$, Tom Reddyhoff ${ }^{\mathrm{b}}$, Daniele Dini ${ }^{\mathrm{b}}$ \\ aDepartment of Mechanical Engineering, Laboratory of Surface Phenomena (LFS), Polytechnic School \\ of the University of São Paulo, São Paulo, Brazil \\ ${ }^{b}$ Department of Mechanical Engineering, Imperial College London, South Kensington Campus, \\ London, UK
}

\begin{abstract}
Recent experiments have shown that automotive piston-liner friction may be reduced by up to $50 \%$ if the surface of the liner is laser textured with certain configurations of micro-pockets. It is important to model this behaviour to understand and optimise the friction reduction mechanisms that are occurring. However, until now, very few models that predict the lubrication performance of textured surfaces have been successfully validated against experimental data. This is due to the requirement for them to (i) reproduce experimental configurations with a certain degree of fidelity, (ii) conserve mass properly, and (iii) account for transient, boundary lubrication conditions. To address this, the current paper presents a comparison between the results from a numerical model, which fulfils these criteria, and an experimental test rig operating under the same conditions. The mathematical modelling is based on the averaged Reynolds' Equation with the Patir \& Cheng's flow factors and the $p-\theta$ Elrod-Adams mass-conserving cavitation model. Simultaneously to the fluid flow solution, the contact pressures that arises from the asperity interactions are also included into the calculations through the well-known stochastic Greenwood and Tripp model for rough contacts. The experimental data is produced using a reciprocating tribometer, whose contact conditions are closely controlled and accurately mimic those found in an automotive piston-liner conjunction. Data is presented in terms of friction force versus stroke angle and the similarities and differences between the model and experiment are discussed.
\end{abstract}

\section{Introduction}

Applying texture to the surface of engineering components as a means of controlling friction has been investigated since the 1960s [1]. The impact of this approach can be significant, with friction reductions of over 50\% being demonstrated in controlled laboratory tests [2], and there is some evidence to suggest that this translates to measurable improvements in overall engine performance [3]. Compared to other energy saving solutions, surface texture is cheap and simple to implement. It does not require components to be redesigned and can be incorporated easily into existing and future technologies.

Despite the potential rewards, surface texturing has largely eluded practical application. One of the reasons for its limited uptake is that, despite its simple concept, the effect of textured surfaces on friction is a challenging phenomenon to predict. This is because texture interacts with, and hence complicates, frictional processes, which themselves depend on intricate interactions between liquids and surface under mixed and boundary lubrication conditions. This is the case particularly under the transient conditions found in piston liner contacts, where surface texture may offer the greatest benefits. 
Numerous models have attempted to predict the textured surface behaviour, which over the years have increased in complexity (see e.g. $[4,5,6,7,8,9,10]$ ). This paper will not provide an in-depth history of these developments as they can be found in several recent reviews, including [11]. The one of the main problems in predicting texture behaviour is that common finite difference methods, which are effective for plain surfaces, are not appropriate for the detailed geometry of pocketed surfaces. Therefore, approaches such as finite element methods (FEM), that can cope with unstructured/irregular grids are required. However, convergence problems arise with traditional FEM approaches when attempting to solve Reynolds equation with Jakobsson, Floberg and Olsson mass conserving conditions [12] through the so-called $p-\theta$ Elrod-Adams formulation $[13,14]$. Therefore, an alternative general finite volume method (FVM) has recently been proposed for solving Reynolds equation with mass-conserving cavitation model on irregular grids and this has been applied to solve textured lubrication problems more effectively [15].

An additional challenge with modelling surface texture is that numerous experiments have shown texture reduces friction in the mixed and boundary regime - but not in the hydrodynamic regime $[16,17,18,2]$. However, the majority of texture modelling $[19,20,21,6]$ have included only hydrodynamic behaviour and have largely ignored mixed lubrication and asperity contact. This means that models of surface texture behaviour should include mixed lubrication effects if they are to be validated experimentally.

In order to address these issues and provide an effective means of predicting the behaviour of surface texture, the current paper puts forward a new combined modelling approach for textured surface lubrication. The mathematical modelling is based on the averaged Reynolds equation with the Patir \& Cheng's flow factors $[22,23]$ and the $p-\theta$ Elrod-Adams mass-conserving cavitation model. Simultaneously to the fluid flow solution, the contact pressures that arises from the asperity interactions are also included into the calculations through the well-known stochastic Greenwood and Tripp model for rough contacts [24].

This model is validated against experimental data that is produced using a reciprocating tribometer, whose contact conditions are closely controlled and accurately represent those found in an automotive piston-liner conjunction. As demonstrated previously, this tribometer has the ability to obtain reliable measurements of film thickness and friction under steady state [25] and transient conditions [26].

\section{Mathematical Modelling}

In this section, a description of the mathematical formulations used in this contribution to model the reciprocating contact between piston ring and cylinder liner under mixed lubrication conditions is presented. The system configuration, along with the main geometric and kinematic parameters adopted in the mathematical models, are illustrated in Figure 1.

\subsection{Fluid Film Lubrication}

The hydrodynamic pressure field developed over the thin lubricant film on the contact interface under mixed lubrication conditions are described through the average Reynolds equation based on the Patir \& Cheng's flow factors formulation [22, 23]. Such modified Reynolds equation is derived by locally averaging the lubricant flows in the presence of roughness irregularities. This provides specific flow factor coefficients that account for the influence of the fluid flow perturbations at the roughness scale 
directly in the global component-size scale. Furthermore, the fluid film cavitation phenomenon that often occurs around liquid lubricated contacts with asymmetric profiles is properly accounted for. Specifically, the $p-\theta$ Elrod-Adams mass-conserving cavitation model [13, 14], which automatically satisfies the complementary JFO conditions for mass-conservation at the cavitation boundaries [12], is adopted for the calculation of the hydrodynamic pressures.

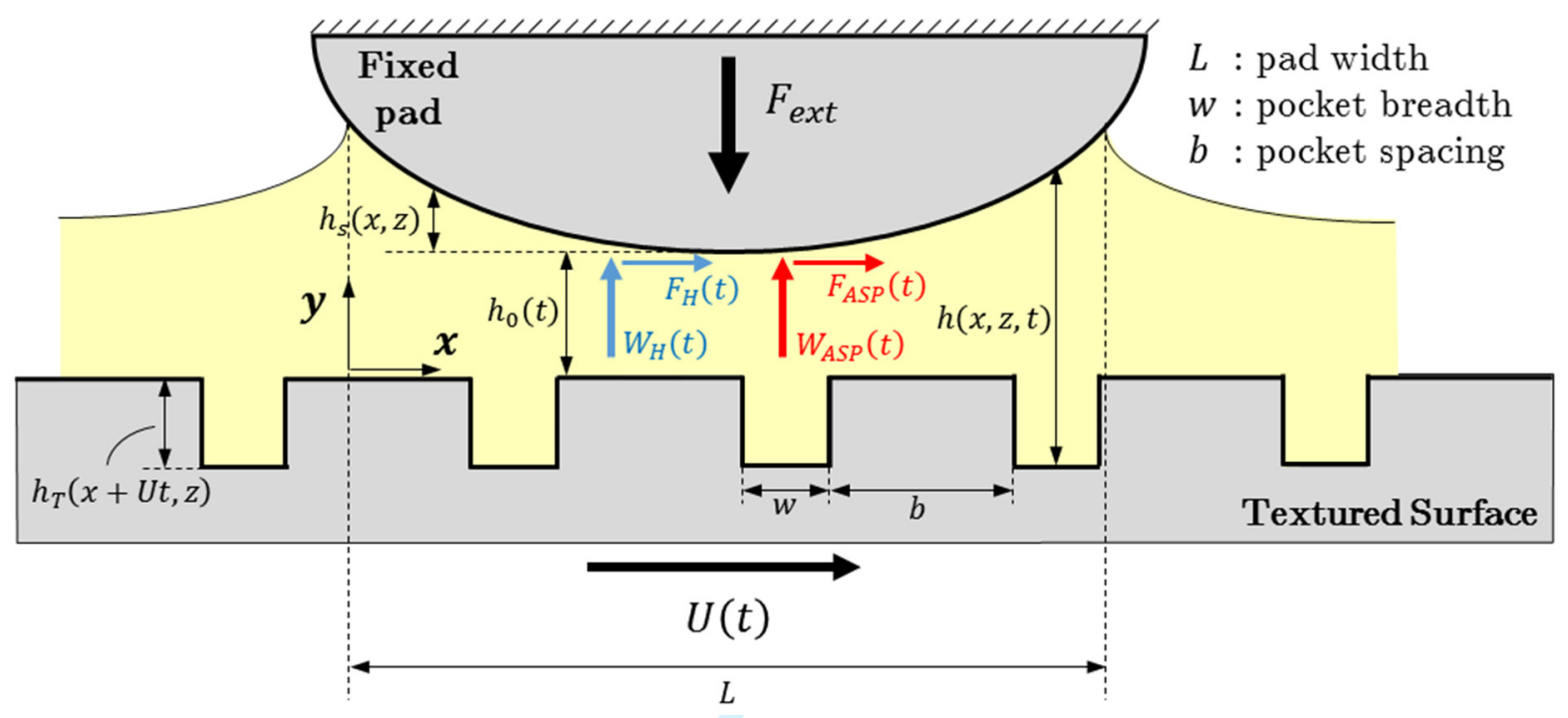

Figure 1 - Schematic view of the piston ring/cylinder liner contact system with moving texture. Notice that the fluid flow problem is described with respect to the fixed pad (piston ring) reference system.

Thus, by assuming the geometric and kinematic configuration illustrated in Figure 1, where the textured slider surface (i.e. cylinder liner sample) moves along the $x$-direction with velocity $U(t)$, the generalized isothermal Reynolds equation can be expressed in the local Cartesian coordinate system (Oxyz) attached to the fixed pad surface (i.e. piston-ring sample) as follows:

$$
\begin{aligned}
& \frac{\partial}{\partial x}\left[\left(\frac{\phi_{p_{x}} h^{3}}{12 \mu}\right) \frac{\partial p_{H}}{\partial x}\right]+\frac{\partial}{\partial z}\left[\left(\frac{\phi_{p_{z}} h^{3}}{12 \mu}\right) \frac{\partial p_{H}}{\partial z}\right]=\frac{\partial}{\partial x}\left[\theta \frac{U}{2}\left(h \phi_{c}-\sigma_{R} \phi_{s_{x}}\right)\right]+\phi_{c} \frac{\partial(\theta h)}{\partial t} \\
& \text { Complementary conditions for cavitation } \\
& \left(p_{H}-p_{\text {cav }}\right)(1-\theta)=0 \rightarrow \begin{cases}p_{H}>p_{\text {cav }} \rightarrow \theta=1 & \text { (pressured regions) } \\
p_{H}=p_{\text {cav }} \rightarrow 0 \leq \theta<1 & \text { (cavitation regions) }\end{cases}
\end{aligned}
$$

where $p_{H}(x, z, t)$ is the hydrodynamic pressure, $\mu$ the lubricant dynamic viscosity, $h(x, z, t)$ the oil film thickness, $U(t)$ the velocity of the slider surface and $\theta(x, z, t)$ the film fraction parameter that represents the proportion of liquid lubricant contained in the cavitation regions where the fluid pressures fall below the saturation and/or vapour pressure of the lubricant $\left(p_{c a v}\right)$. The coefficients $\phi_{p_{x}}$ and $\phi_{p_{z}}$ are the pressure flow factors, $\phi_{s_{x}}$ the shear flow factor along the sliding motion, $\sigma_{R}$ is the combined standard deviation of the surface roughness and $\phi_{c}$ the contact factor that can be estimated as a function of the statistical 
distribution of the roughness heights [27, 28]. According to Figure 1, the lubricant film thickness expressed in the coordinate system $O x y z$ can be written as:

$$
h(x, z, t)=h_{T}\left(x+\int_{0}^{t} U(\tau) d \tau, z\right)+h_{s}(x, z)+h_{0}(t),
$$

where $h_{T}$ is the instantaneous geometry of the textured slider surface in the reference system $O x y z, h_{s}$ the fixed geometry of the pad surface and $h_{0}$ the minimum film thickness associated with the normal rigid body motion of the contact surfaces (normal squeeze effect). Moreover, solid deformations and non-Newtonian lubricant rheology (i.e. piezoviscous and shear-thinning effects) linked to elastohydrodynamic (EHL) contacts were neglected in the present analysis. However, these features can easily be added to the formulations to solve problems in which their effect becomes significant and their incorporation is necessary $[4,29,30]$.

The numerical solution of Eq. (1) with the appropriated pressure boundary conditions is performed using the hybrid-type finite volume discretization scheme, namely Finite Volume Method based on Elements, recently published by the authors for the general solution of Reynolds equation with mass-conserving cavitation model on irregular meshes [15]. In the proposed solution framework, the simultaneous calculation of the hydrodynamic pressure $\left(p_{H}\right)$ and film fraction $(\theta)$ fields established in Eq. (1) is realized based on a generalization of the cavitation algorithm proposed by Ausas and co-workers [31].

Local interference

Plane and (asperity deformation)

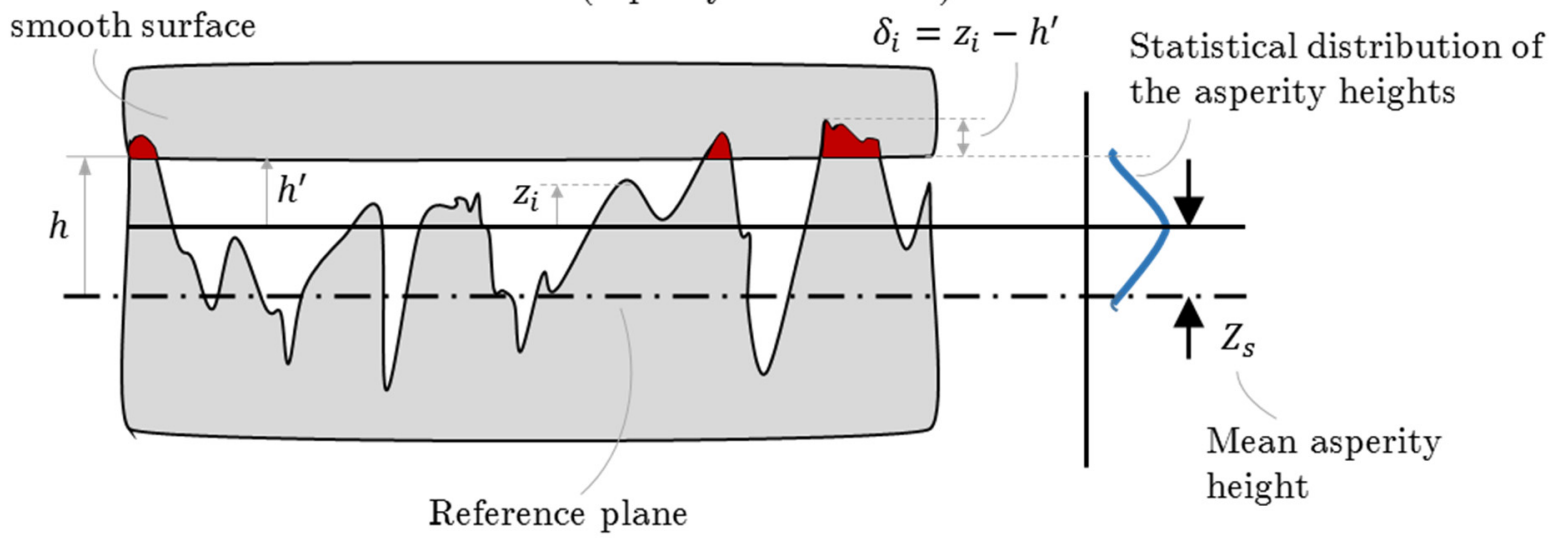

Figure 2 - Contact between a rigid, smooth plane against a rough surface illustrating the main variables of the Greenwood-Tripp model for rough contact.

Since the instantaneous geometry of the slider surface verified in the reference system $(O x y z)$ changes with time as the pockets move through the pad, an interpolation procedure was adopted at each time step of the transient solution. This transferred the instantaneous slider (cylinder liner) geometry to a fixed numerical mesh attached to the pad surface, from which Reynolds equation is solved. Additionally, special attention was given to the interpolation process in order to preserve all texture features in the fluid mesh that are important for the proper assessment of the hydrodynamic and asperity contact phenomena. 


\subsection{Asperity Contact Model}

The asperities covering the contact surfaces under mixed lubrication conditions tend to mechanically interact to each other at the roughness scale, thus yielding micro-contact pressures which collectively contribute to the overall load carrying capacity of the system. The calculation of such contact pressures for a given surfaces separation is here estimated through the well-known stochastic Greenwood-Tripp (GT) model for rough contacts [24]:

$$
p_{A S P}=\left\{\begin{array}{c}
\frac{16 \pi \sqrt{2}}{15} E^{*}\left(\eta_{s}{ }^{2} \beta_{s}^{3 / 2} \sigma_{s}^{5 / 2}\right) F_{5 / 2}(\bar{h}), \quad p_{A S P}<H_{V}, \\
H_{V}, \quad p_{A S P} \geq H_{V}
\end{array}\right.
$$

where $p_{A S P}(x, \mathrm{z}, t)$ is the asperity contact pressure and $\bar{h}(x, \mathrm{z}, t)=\left(\frac{h-Z_{S}}{\sigma_{S}}\right)$ the dimensionless separation distance between the matching surfaces. Furthermore, the following combined contact parameters are defined: $Z_{s}$ the asperity mean height, $\sigma_{s}$ the asperity heights standard deviation, $\beta_{s}$ the asperity mean curvature radius and $\eta_{s}$ the asperity density. Such contact parameters are deterministically calculated from 3D surface roughness measurements using a dedicated in-house code developed in accordance with the methodologies and criteria described in [32] (see Figure 2). The mechanical properties of the surfaces are considered through the composite elastic modulus, $E^{*}$, and the Vickers' hardness of the softer material, $H_{V}$. Setting the threshold of the contact pressures to $H_{V}$ extend the application of the original pure elastic GT formulation to elastic-perfectly plastic contacts. The integral function $F_{5 / 2}(\bar{h})$ represents the random distribution of the asperity heights, which for a Gaussian distribution can be approximated by a 6 th-order polynomial as follows:

$$
\begin{array}{r}
F_{5 / 2}(\bar{h})=\frac{1}{\sqrt{2 \pi}} \int_{\bar{h}}^{\infty}\left[(s-\bar{h})^{5 / 2} e^{-\frac{s^{2}}{2}}\right] d s \approx \sum_{\mathrm{i}=0}^{6} \mathrm{a}_{\mathrm{i}} \bar{h}^{\mathrm{i}},-3<\bar{h}<3 \\
\text { with } \mathrm{a}_{0}=\begin{array}{r}
6.153 .10^{-1} ; \mathrm{a}_{1}=-1.085 .10^{0} ; \mathrm{a}_{2}=7.764 .10^{-1} ; \mathrm{a}_{3}=-2.575 .10^{-1} ; \\
\mathrm{a}_{4}=2.825 .10^{-2} ; \mathrm{a}_{5}=3.348 .10^{-3} ; \mathrm{a}_{6}=-6.717 .10^{-4}
\end{array}
\end{array}
$$

Notice that despite its limitations use of the GT model is still widespread for rough contact calculations. This is mainly due to the simple computational implementations; nevertheless, this methodology has proven to be robust and efficient to provide satisfactory predictions for design purposes. However, more advanced methodologies based on homogenisation techniques applied to fully-deterministic calculations can also be easily incorporated in the current framework.

\subsection{Equilibrium and Total Friction Equations}

In the mixed lubrication regime, the normal external loads acting on the contact surfaces are balanced by both the hydrodynamic and asperity contact pressures developed on the interface. Thus, assuming that the mass of the surfaces is small, so that inertial effects can be neglected, the following quasi-static equation is obtained in the $y$-direction (see Figure 1): 


$$
W_{H}(t)+W_{A S P}(t)=F_{\text {ext }}(t)
$$

where $W_{H}(t)$ and $W_{A S P}(t)$ are the instantaneous lift forces produced by the hydrodynamic and asperity contact pressures, which can be rewritten considering the integration of the pressures distributions over the pad domain as:

$$
\int_{-B / 2}^{B / 2} \int_{L / 2}^{-L / 2}\left[p_{H}(x, z, t)+p_{A S P}(x, z, t)\right] d x d z=F_{\text {ext }}(t),
$$

where $B$ and $L$ are the pad length and width, respectively. For transient problems such as the reciprocating motion system considered in the present work, the nonlinear equilibrium equation defined above is solved at each time step using a Newton-Raphson algorithm. This determines the minimum lubricant film thickness $h_{0}(t)$ and the associated fluid and contact pressures that balance the external load force for a given instantaneous sliding velocity of the textured surface. Analogously, the total friction force acting on the pad surface can be calculated as a combination of the dissipative forces linked to hydrodynamic and rough contact effects. Accordingly:

$$
F(t)=\int_{-B / 2}^{B / 2} \int_{L / 2}^{-L / 2}[\underbrace{\left(\frac{h}{2} \frac{\partial p_{H}}{\partial x} \phi_{f p_{x}}+\frac{\mu \theta U}{h}\left(\phi_{f}-\phi_{f s_{x}}\right)\right)}_{\tau_{H}(t)}+\underbrace{\left(\mu_{b c} p_{A S P}\right)}_{\tau_{A S P}(t)}] d x d z,
$$

where $\mu_{b c}$ is the boundary coefficient of friction that depends on the tribological film formed on the interface and is assumed to be known a priori from experiments, and $\tau_{H}(t)$ and $\tau_{A S P}(t)$ are the respective hydrodynamic and asperity contact shear stresses. Moreover, $\phi_{f s_{x}}$ and $\phi_{f}$ are the respective shear stress flow factor along the sliding direction and the friction factor, both defined in the Patir \& Cheng's average model $[22,23]$. Notice that the influence of the hydrodynamic pressure on the horizontal force has been neglected since the combination of high pad curvature $(\sim 40 \mathrm{~mm}$, see Section 3.1$)$ and small film thickness (mixed lubrication regime) that characterize the problem in study considerably attenuates the effect of the component of the fluid pressure in the direction of motion [33]. On the other hand, the influence of the hydrodynamic pressure developed at the roughness scale is taken into account through the pressure shear flow factor $\phi_{f p_{x}}$.

\section{Description of the Experimental Tests}

A reciprocating optical test rig was designed and built for the purpose of this project, with the aim of studying friction, film thickness and cavitation behaviour in lubricated non-textured and textured surfaces, all in situ and simultaneously. 
A low capacity isometric load cell is held in permanent, direct contact with a special specimen holder mechanism, in order to measure friction between the surfaces in contact: an AISI 52100 steel pad (replicating the piston ring) and the counterpart fused silica specimen (replicating the cylinder liner). Two steel shims are used to displace the upper part of the specimen holder away from or towards the load cell. A voltage differential results from the specimen holder deflecting due to friction forces in the reciprocating contact, voltage which is proportional to the level of deflection. In addition, the special holder mechanism was designed to also allow for the self-alignment of the steel test specimen to the steel pad. The main structural features of this mechanism are shown in Figure 3.

Two nozzles attached to the oil bath deliver lubricant to the contact area. Dead weights of accurately controlled dimensions, attached to the silica pad holder, are used to apply an operating normal load (W).

An electric motor drives an adjustable stroke mechanism, generating the reciprocal motion of the fused silica pad along two linear bearings. An in-depth description of the test rig can be found in [2].

The current study involves only friction measurements, however, it should be noted that this experimental setup includes the facility to measure film thickness accurately in the boundary, mixed and full film regimes. This is achieved using a modified version of the optical interferometry technique based which uses the out-of-contact curvature of the specimen in place of a spacer layer and enables film thicknesses of less than $50 \mathrm{~nm}$ can be measured under transient, mixed lubrication conditions, as described in [25].

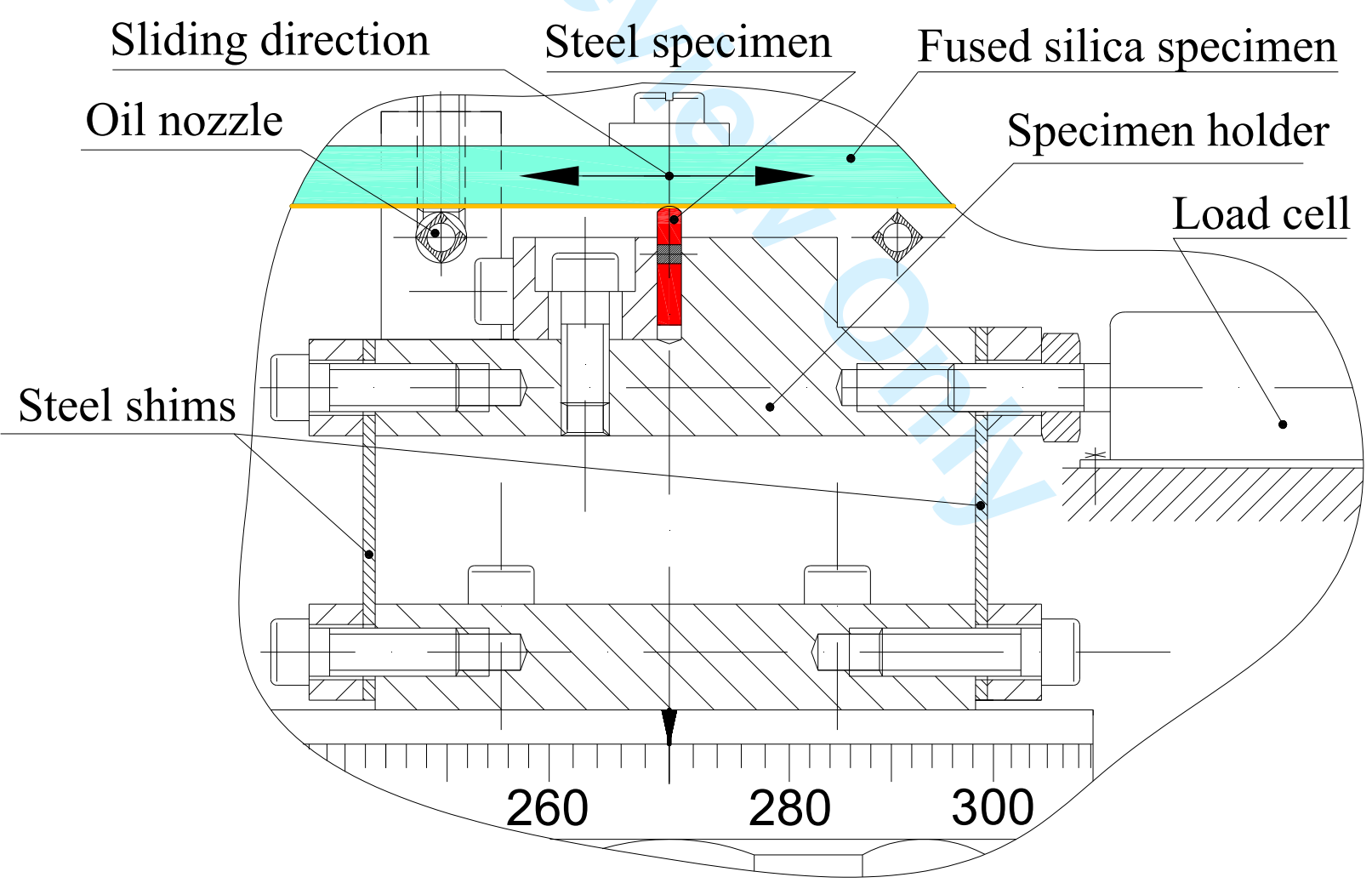

Figure 3 - Schematic representation of the in-house developed experimental set-up. 
Finally, an additional optical technique can be employed to visualise cavitation zones and accurately evaluate their patterns. This technique, based on the photo-excitation of a fluorescent dye, Laser Induced Fluorescence (L.I.F), and its images of cavitation will be used in future work to further validate the modelling results.

\subsection{Specimens and Experimental Procedure}

The HPFS Standard Grade fused silica pad was textured with micro-pockets along the entire $28.6 \mathrm{~mm}$ stroke length. Three different patterns were selected for this study and laser-etched onto the sample pads. Figure 4 below shows the 3D optical profiles of the three samples, including the shape and geometry of the features and their positioning relative to the sliding direction. For a precise assessment of the influence of pocket breadth on friction, pocket depth was maintained constant at $8 \mu \mathrm{m}$ and pocket density was held at $1100 \mu \mathrm{m}$. The friction results obtained by using these specimens were compared against those generated by a non-textured reference sample.

The counterpart barrel-shaped steel specimen is $10 \mathrm{~mm}$ long, $2 \mathrm{~mm}$ wide and curved at a radius of $40 \mathrm{~mm}$ to achieve a convex shape in the direction of sliding. The process of polishing this curved surface was carefully controlled by using an accurate grinding jig as presented in [26], which allowed a precise finish along the entire $10 \mathrm{~mm}$ length. A 3D surface plot of the convergent-divergent steel specimen, recorded by the Veeco Wyko NT9100 optical profiler and including roughness specifications, is illustrated in Figure 5 .

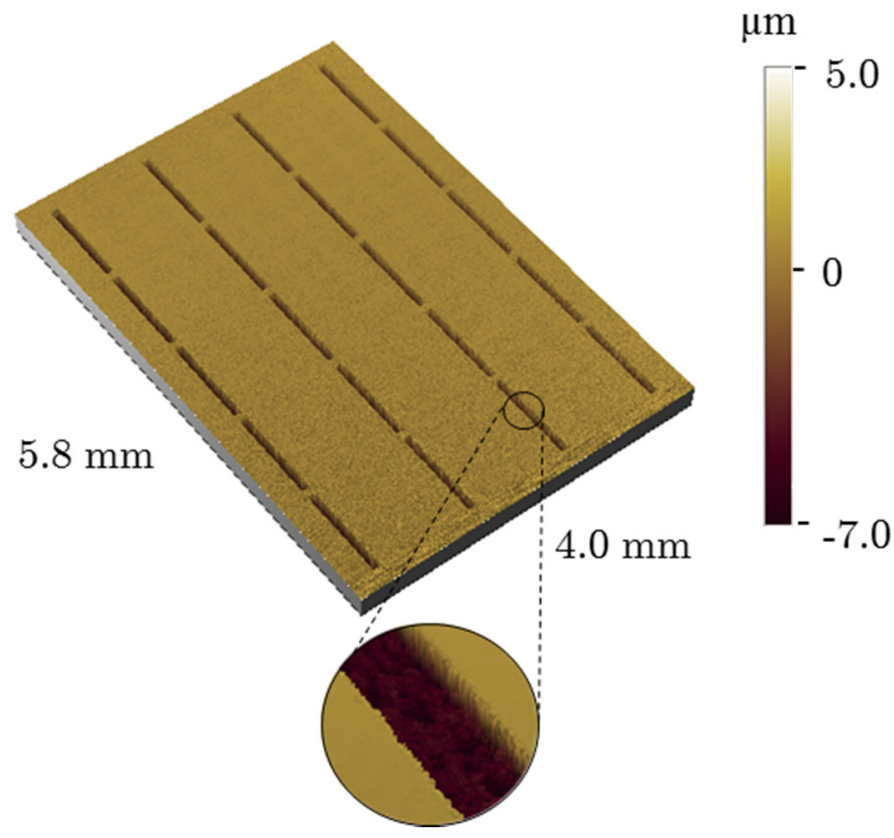

\begin{tabular}{cc}
\multicolumn{2}{c}{$80 \times 8 \times 1100$} \\
\hline Pocket Breadth & $80 \mu \mathrm{m}$ \\
\hline Pocket Depth & $8 \mu \mathrm{m}$ \\
\hline Gap between pockets & $1100 \mu \mathrm{m}$ \\
\hline
\end{tabular}

Figure 4 - Three dimensional surface plot of the laser surface textured fused silica specimen with pocket breadth $80 \mu \mathrm{m}$.

Multiple iterations of friction tests were performed using the three textured configurations as well as the non-textured reference sample. The results are graphically represented for a constant applied normal load of $70 \mathrm{~N}$ and reciprocation frequency of $3 \mathrm{~Hz}$. Lubricant temperature was set at $60^{\circ} \mathrm{C}$ for the full range of testing sequences. Given the velocity limitations of the test apparatus, this 
temperature was found to represent the optimal value at which the bearing could be positioned in different locations along the mixed lubrication regime.

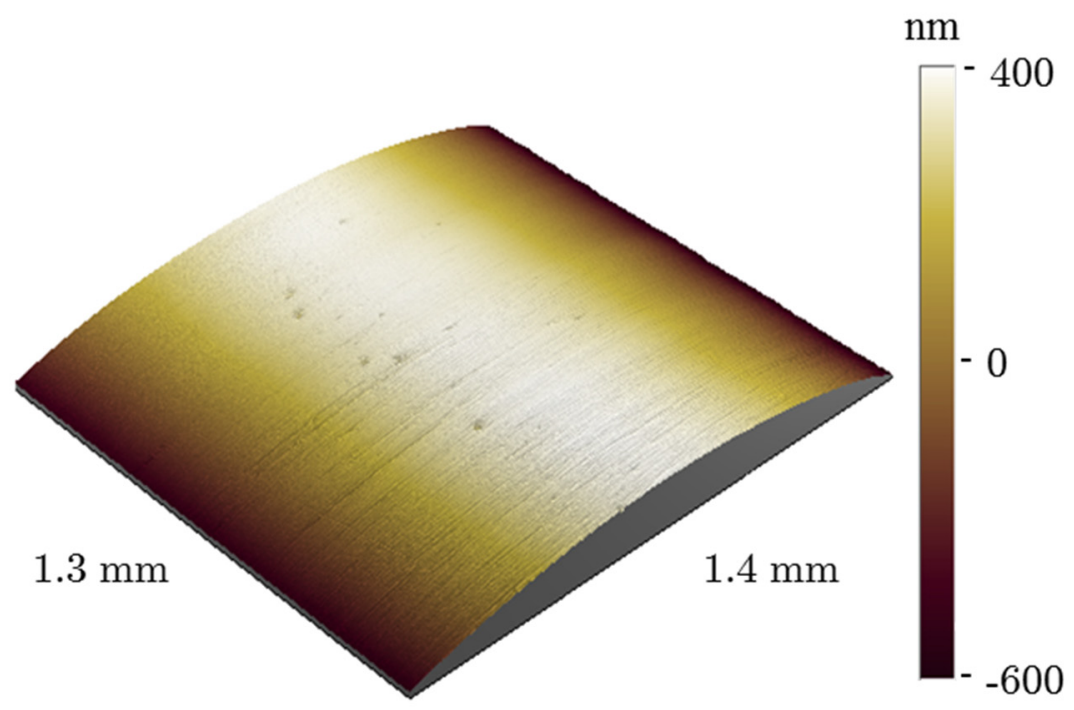

Figure 5 - Three dimensional surface topography of the barrel-shaped steel specimen as obtained by the Veeco Wyko optical profiler.

Friction data was recorded as a function of crank angle along the full stroke trajectory, for each testing instance. Friction force graphs were generated for two full revolutions of the adjustable stroke rotating mechanism, representing four strokes of the silica pad.

\section{Results and Discussion}

\subsection{Simulations set-up and test cases}

The validation of the mathematical modelling presented in Section 2 is evaluated through comparisons with the experimental results of the reciprocating friction test with pocketed surface described in Section 3. As already mentioned, an important issue associated with the simulation of moving textures is the instantaneous match of the textured slider geometry with the fluid mesh attached to the fixed pad. Figure 6 depicts the instantaneous geometries of the textured slider projected on the pad mesh for different positions along the stroke. The hydrodynamic and asperity contact problems are solved simultaneously on the pad grid at every time step. A time step of $\Delta t=9.2 \times 10^{-5} s$ was set such that the increments of the sliding displacement are at least four times smaller than the pockets breadth to ensure a proper discretization of the local texture features throughout the reciprocating motion. For this time step, the element size of the fluid mesh along the sliding direction was $11.5 \mu \mathrm{m}$, which provided a full pad grid with 23450 elements (see Figure 6). 

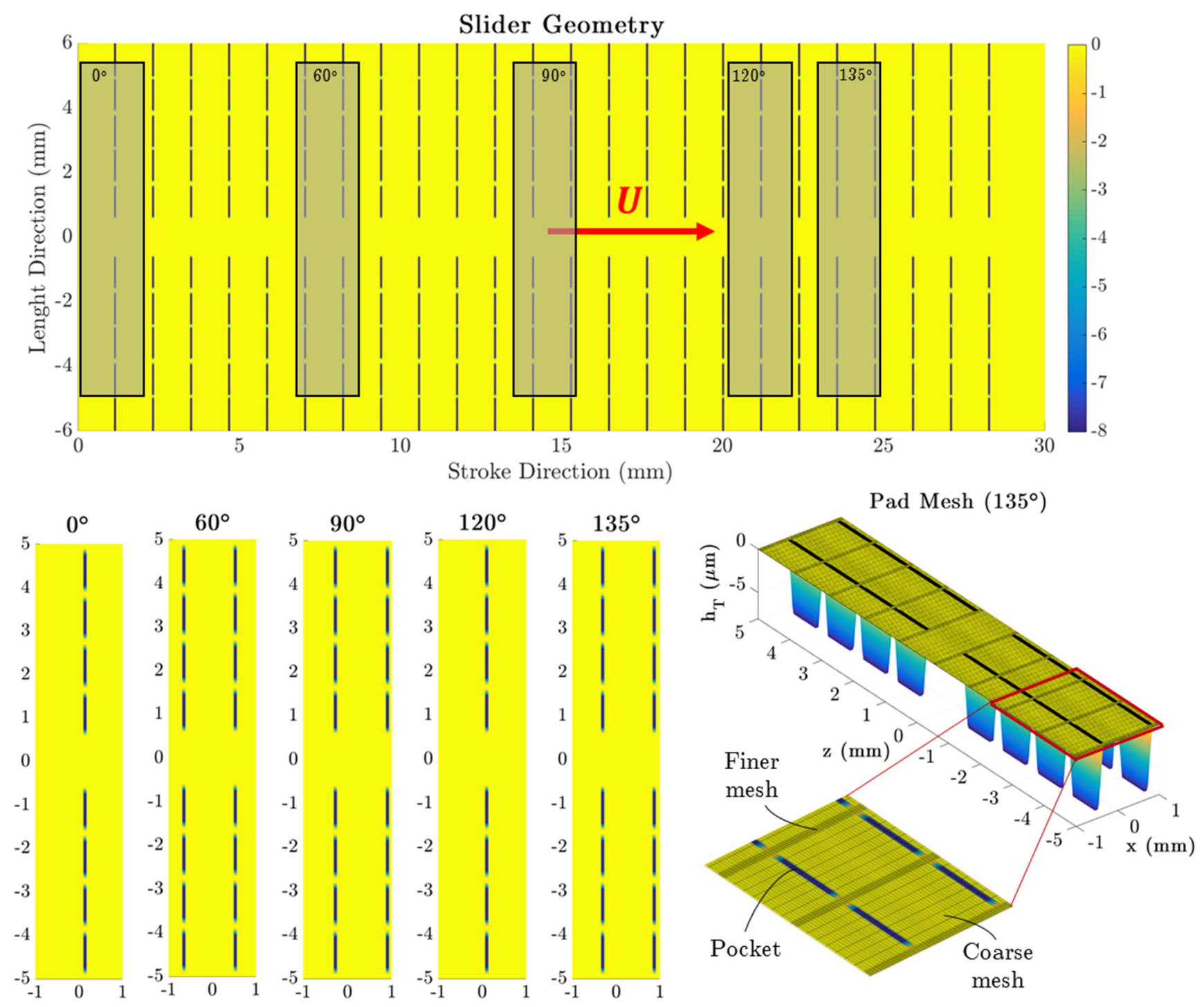

Figure 6 - Entire geometry of the textured slider and representative "instantaneous" geometries projected on the pad mesh for the $0^{\circ}, 60^{\circ}, 90^{\circ}, 120^{\circ}$ and $135^{\circ}$ stroke positions.

The lubricant and material properties adopted in the simulations are listed in Table 1. The general test conditions and the Greenwood-Tripp contact parameters calculated from the 3D roughness measurements shown in Figure 4 and Figure 5 are also displayed in the table. The value of the boundary friction coefficient $\mu_{B L}$ was chosen in accordance with the experimental friction forces measured at the reversal points of the reciprocating cycle where the boundary lubrication regime tend to be more pronounced due to the lower magnitudes of the sliding speed (which goes to zero at the end points of the cycle). Moreover, the flow factors coefficients adopted in the simulation cases with the average flow model were estimated using the curves originally proposed by Patir \& Cheng for Gaussian roughness heights distribution $[22,23]$. As for the orientation of the roughness heights also necessary for the correct use of the Patir \& Cheng model and represented by the surface pattern parameter $\gamma$, the textured slider and the pad surfaces were assumed to be isotropic $(\gamma=1)$ and longitudinally $(\gamma=9)$ oriented, respectively. These surfaces patterns were assumed in accordance with the correlation lengths ratio calculated from the 3D roughness measurements shown in Figure 4 and Figure 5. 


\subsection{Experimental vs. Simulation Results}

The beneficial effect of transversal oriented pockets depicted in Figure 4 on friction reduction under mixed lubrication conditions verified experimentally for the reciprocating test described in Section 3 and already reported in reference [2] is shown in Figure 7. The results suggest that the textures act to increase fluid entrainment and hence reduce asperity contact. The following discussions is devoted to the experimental validation of the mixed lubrication modelling proposed in the present contribution for the non-textured and textured slider surface cases illustrated in Figure 7, as well as the evaluation of the physical phenomenon taking place at the local roughness scale responsible for the friction reductions observed experimentally in the presence of textures.

Table 1 - Input parameters for the reciprocating test simulations.

\begin{tabular}{|c|c|c|c|}
\hline \multirow{2}{*}{ Parameter } & \multicolumn{2}{|c|}{ Values } & \multirow[b]{2}{*}{ Unit } \\
\hline & $\begin{array}{c}\text { Slider } \\
\text { (fused silica) }\end{array}$ & $\begin{array}{c}\text { Pad } \\
\text { (AISI 52100 steel) }\end{array}$ & \\
\hline$E$ & 72.7 & 210 & $\mathrm{GPa}$ \\
\hline$v$ & 0.17 & 0.30 & - \\
\hline$H$ & 1000 & 850 & $\mathrm{HV}$ \\
\hline$S a$ & 0.068 & 0.088 & $\mu \mathrm{m}$ \\
\hline$S q$ & 0.085 & 0.102 & $\mu \mathrm{m}$ \\
\hline$Z_{S}$ & 0.11 & 0.10 & $\mu \mathrm{m}$ \\
\hline$\sigma_{S}$ & 0.06 & 0.07 & $\mu \mathrm{m}$ \\
\hline$\beta_{S}$ & 5.81 & 4.84 & $\mu \mathrm{m}$ \\
\hline$\eta_{S}$ & $6.01 \times 10^{10}$ & $4.64 \times 10^{10}$ & $\mathrm{~m}^{-2}$ \\
\hline$\gamma$ & 1 & 28 & - \\
\hline$\mu_{B L}$ & \multicolumn{2}{|c|}{0.12} & - \\
\hline \multicolumn{4}{|c|}{ Test Conditions } \\
\hline Stroke & \multicolumn{2}{|c|}{28.6} & $\mathrm{~mm}$ \\
\hline Frequency & \multicolumn{2}{|c|}{3} & $\mathrm{~Hz}$ \\
\hline Load & \multicolumn{2}{|c|}{70} & $\mathrm{~N}$ \\
\hline \multicolumn{4}{|c|}{ Lubricant Properties } \\
\hline Temperature & \multicolumn{2}{|c|}{60} & ${ }^{\circ} \mathrm{C}$ \\
\hline Viscosity & \multicolumn{2}{|c|}{35.09} & $\mathrm{mPa} . \mathrm{s}$ \\
\hline Density & \multicolumn{2}{|c|}{841} & $\mathrm{~kg} / \mathrm{m}^{3}$ \\
\hline
\end{tabular}

The comparison between experimental and simulated friction results for the non-textured slider surface through a full reciprocating cycle is depicted in Figure 8. The typical "barrel-shaped" curve observed in mixed lubricated contacts when the system undergoes reciprocating sliding was readily detected in the simulations. The magnitude of the friction forces progressively decreased from the reversal points and reached a minimum at the mid-stroke, where sliding speed is highest so that the hydrodynamic load support is more effective. According to Figure 8, the simulation results calculated considering the Patir \& Cheng (PC) average flow model (green line) yielded higher friction forces compared with the same simulation case computed without the consideration of the flow factors coefficients (blue line), and also approached more thoroughly the experimental results. Such an increase in the friction forces obtained 
with the PC model is physically linked to the combined effect of roughness and sliding at the local scale, which explains the improvement in the agreement between simulation and experiment, even at stroke positions close to the reversal points where the lubrication condition is more severe and the contribution of contacting asperities is highest.

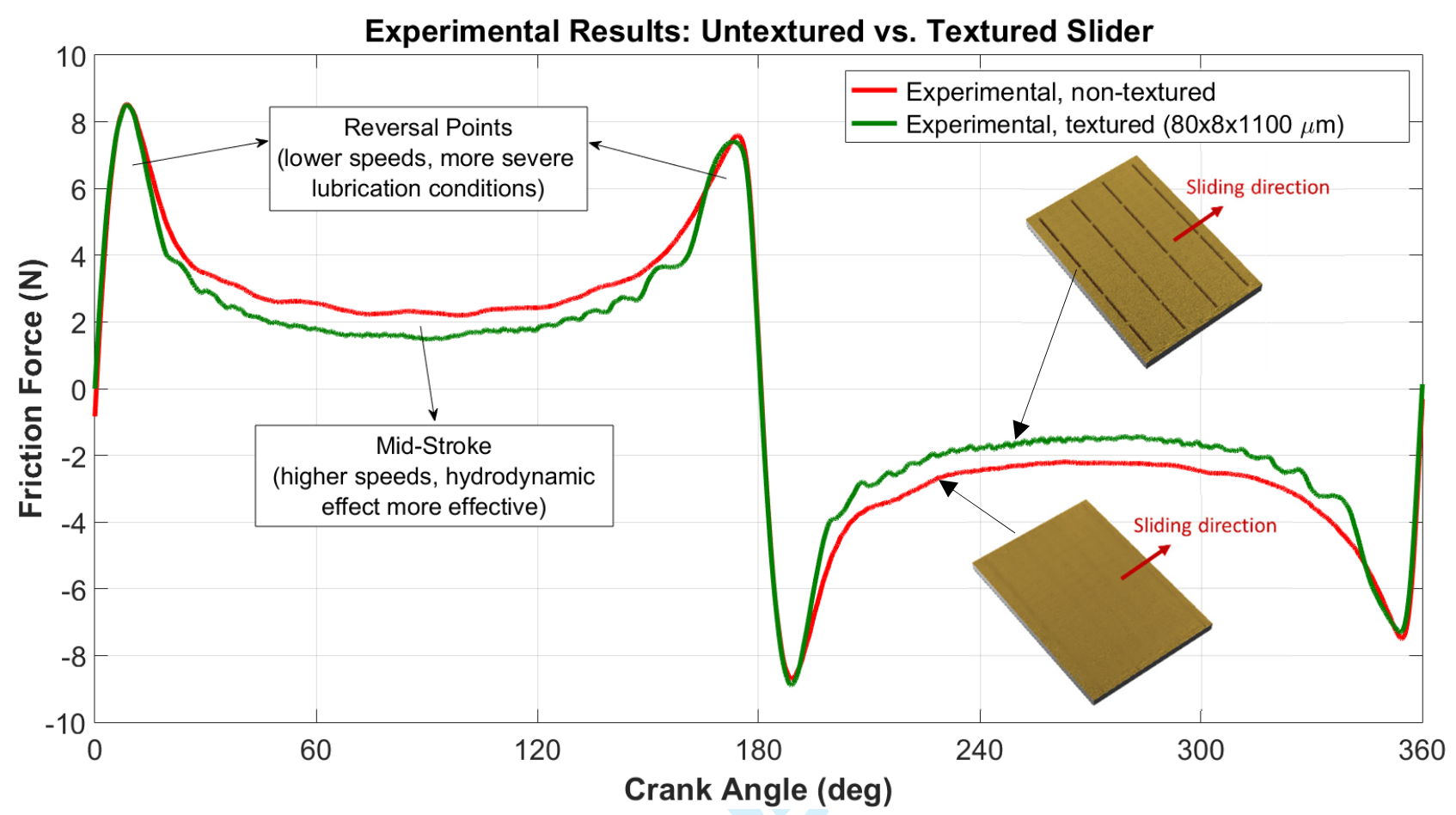

Figure 7 - Friction force comparison between non-textured and textured slider surfaces under mixedlubrication regime (frequency: $3 \mathrm{~Hz}$, normal load: $70 \mathrm{~N}$, oil temperature $60^{\circ} \mathrm{C}$ ).

Despite the satisfactory match between experiments obtained from experiments and simulations for the non-textured surface case, the small discrepancy still observed when PC model is used can be explained by the well-known overestimation of the contact pressure associated with the Greenwood-Tripp model $[34,35,36]$.

Similarly, Figure 9 illustrates the experimental and simulation results for the textured slider case whose representative numerical meshes are shown in Figure 6. As can be seen in Figure 9, the reduction in the friction losses observed experimentally in the presence of textures were also detected in the numerical simulations. Furthermore, the agreement between experiments and simulations was once again more effective when Patir \& Cheng's model is considered. Moreover, the notable fluctuations in the calculated friction forces are associated with the transient effects produced by the variable instantaneous geometry of the textured slider running through the fixed pad, which locally affect the hydrodynamic and asperity contact contributions to the total frictional dissipations, i.e. $F_{\text {Total }}=F_{\text {hydro }}+F_{\text {asp }}$. A detailed illustration showing both the influence of the moving texture condition and the consideration of the PC model on the variation of the friction components is depicted in Figure 10. As expected, the total friction force is ruled by the rough contact effects since the regime is predominantly mixed. Furthermore, it is worth noting the significant periodic decrease in the contact friction and the simultaneous rise in the 
hydrodynamic losses that clearly follows the periodicity of the local gap geometry; these features are more prominent when the PC model is used due to lower film thickness induced by the longitudinally oriented pad surface. The instantaneous film thickness, hydrodynamic pressure, film fraction (cavitation) and asperity contact pressure at the crank angle positions of $87^{\circ}$ (high asperity contact) and $89^{\circ}$ (low asperity contact) are also illustrated in Figure 10(a) and (b) for the simulations run without and with $P C$ respectively. In these cases it is possible to directly observe the increase in contact pressure caused by the lower oil film when PC model is considered. Such trend is obviously not present in the nontextured case and may be considered as the main localized physical mechanism responsible for the overall friction reductions induced by pockets in the reciprocating cycle. Furthermore, although not presented in the current experimental results, similar fluctuations in the friction force due to the entrainment of individual pockets has recently been observed experimentally [26].

\section{Conclusions}

A new methodology has been proposed to study the effect of microscopic texturing on the frictional response to reciprocating sliding in configurations that mimic the contact between piston-rings and cylinder liners. The novelty of such methodology refers to the following aspects covered throughout the article: (1) development of an integrated mixed lubrication model for moving surfaces based on classical stochastic formulations to account for surface roughness effects on lubrication; (2) use of a new recently published FVM scheme for solving Reynolds equation with mass-conserving cavitation model in the presence of surface texturing; (3) experimental validation of the proposed mathematical modelling and solution framework under the transient conditions of a reciprocating friction test with textured surfaces. For the non-textured case, the model shows very good agreement with experimental results obtained under the same conditions. It is also shown that the proposed model is capable of capturing the difference in behaviour between non-textured and textured surfaces observed experimentally using well-controlled laboratory tests. Furthermore, the model has also been used to explore the mechanisms responsible to the overall friction reduction induced by the transient effect due to the presence of the texture and their entrainment within the contact and related cavitation and asperities contact evolution. This has shed light on the mechanisms of lubrication in these contacts and will be followed more in-depth analyses, which are likely to identify the interplay between mechanisms responsible for friction reduction in a number of other configurations. 


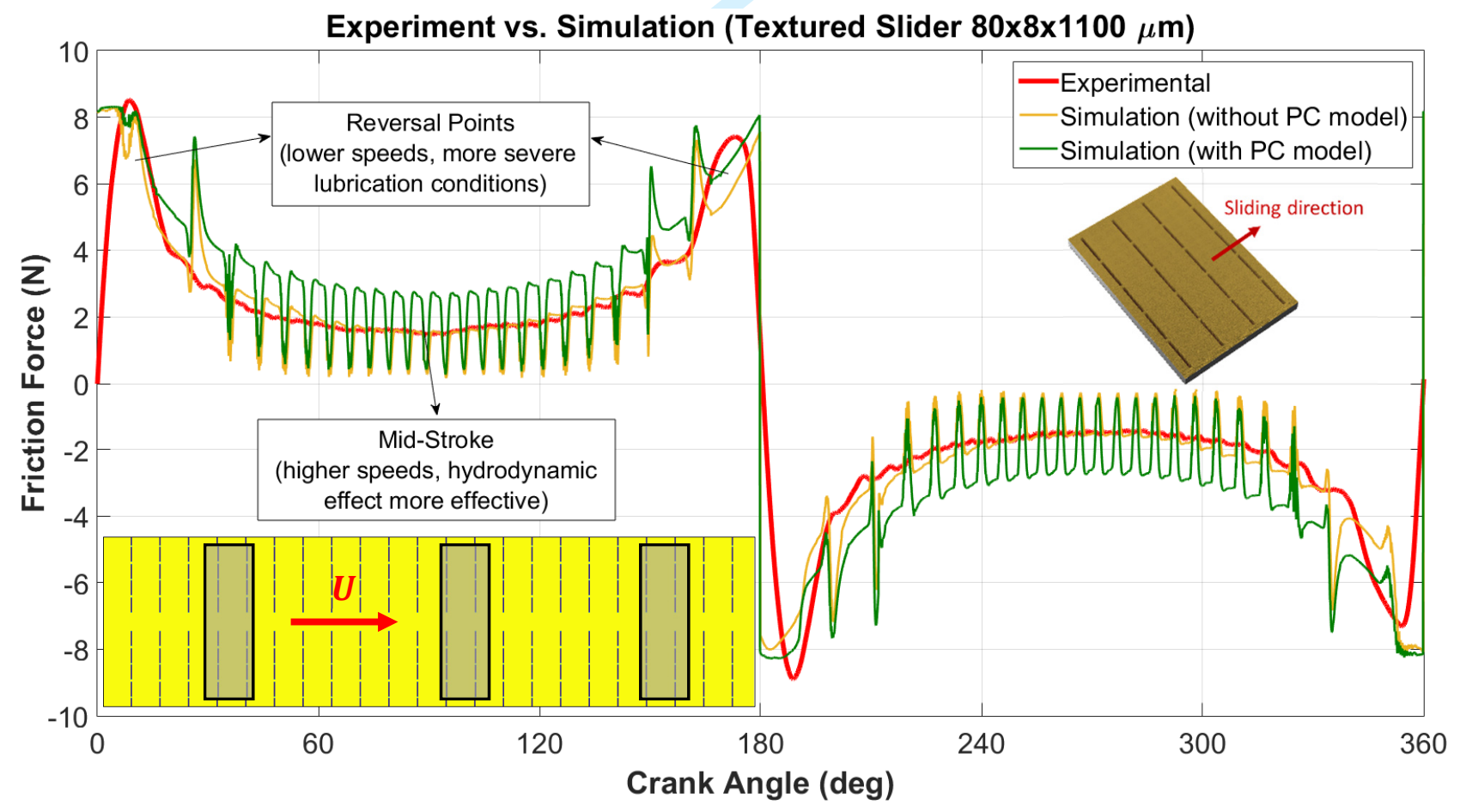

Figure 9 - Comparison between experimental and simulation results for the textured slider surface with 80x8x1100 $\mu \mathrm{m}$ pockets dimensions under mixed-lubrication regime (frequency: $3 \mathrm{~Hz}$, normal load: 70 $\mathrm{N}$, oil temperature $60^{\circ} \mathrm{C}$ ). 

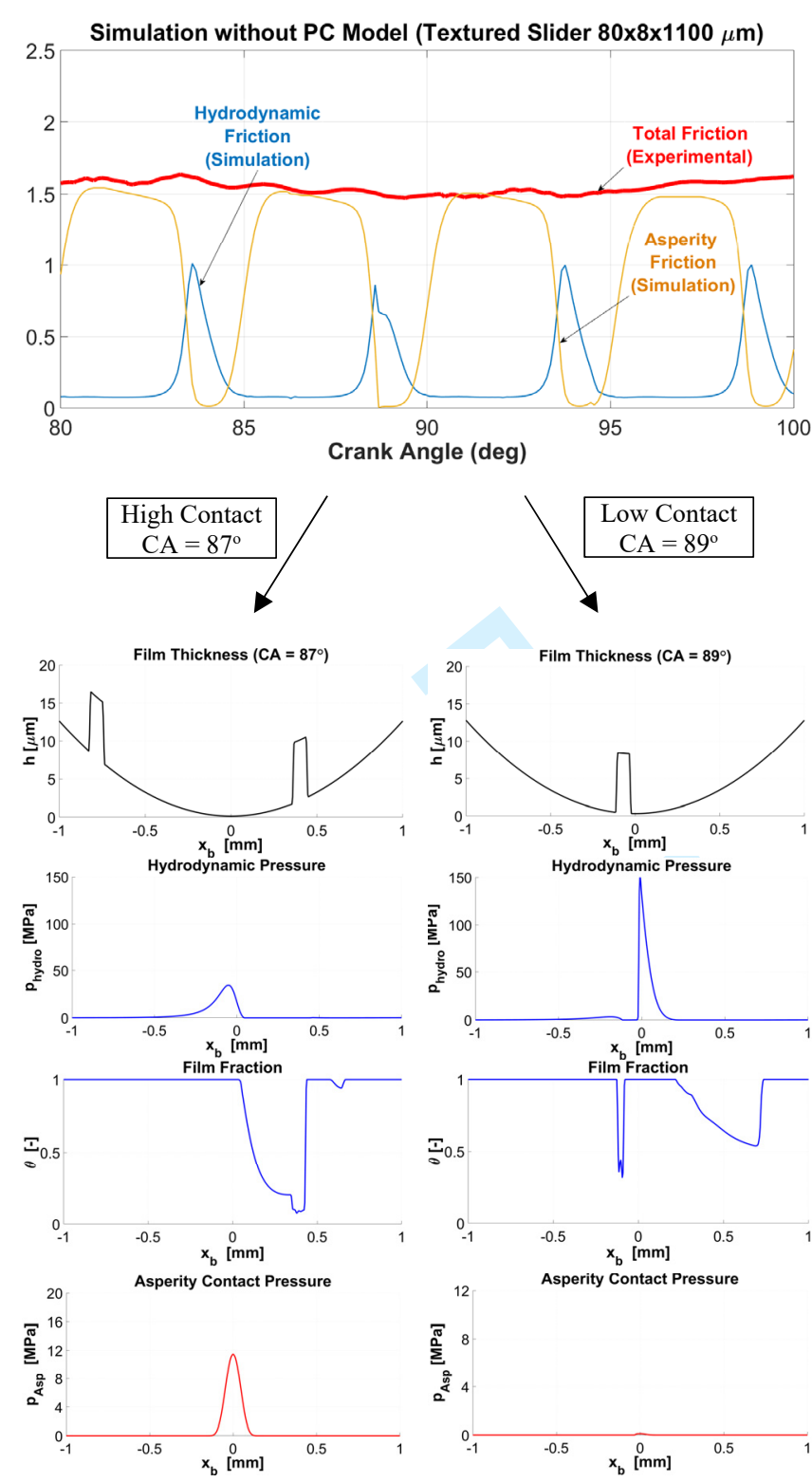

(a)
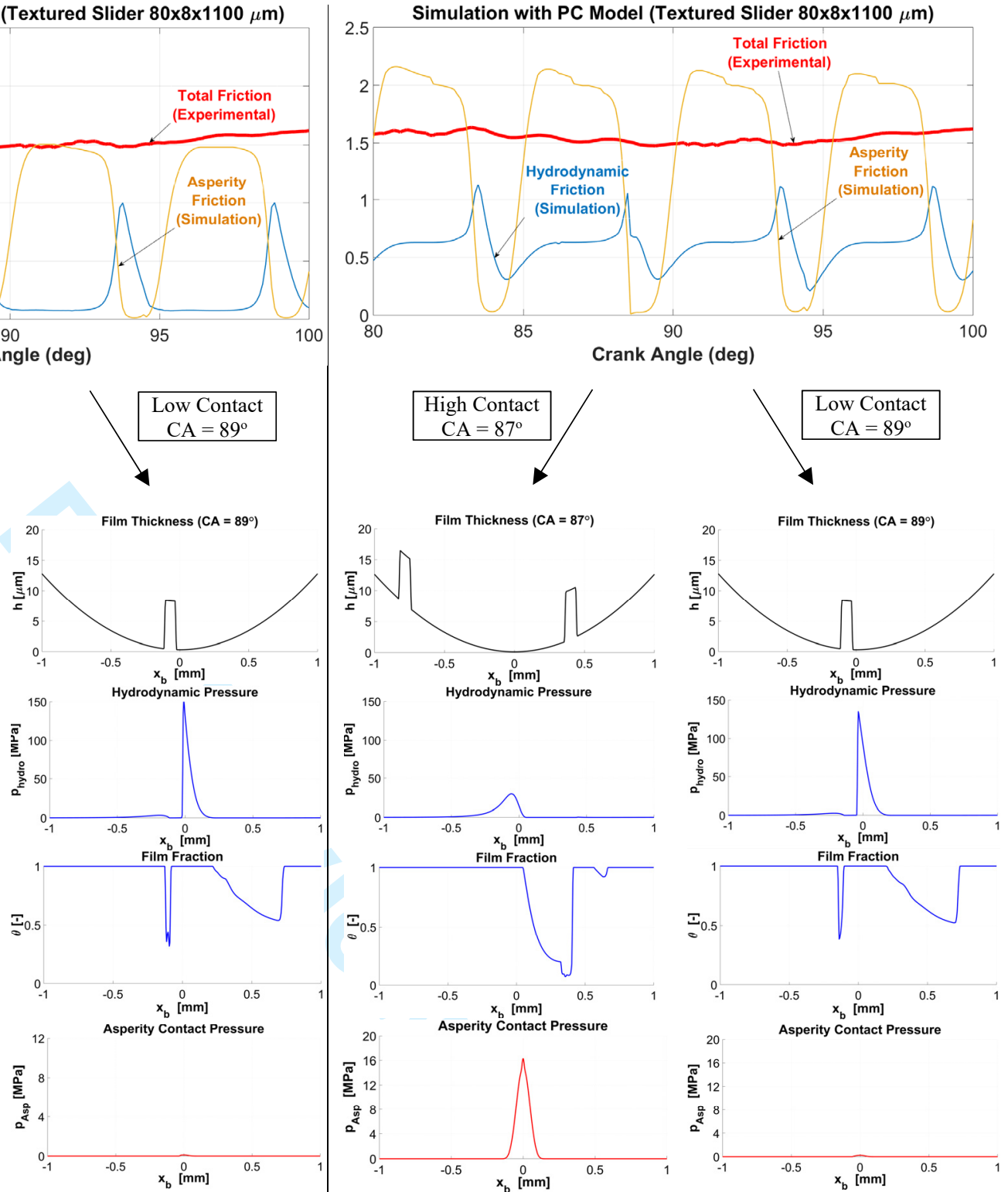

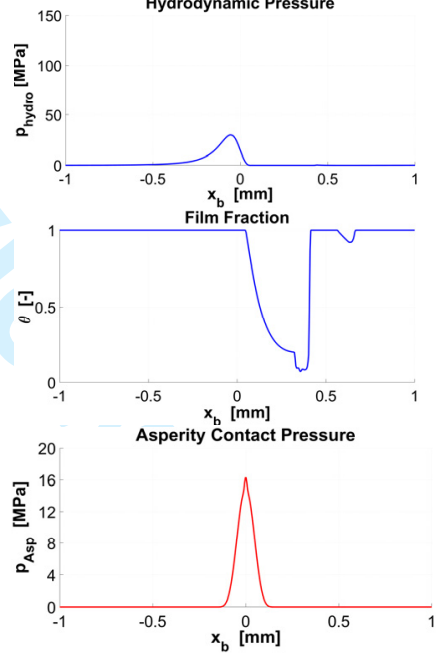

(b)
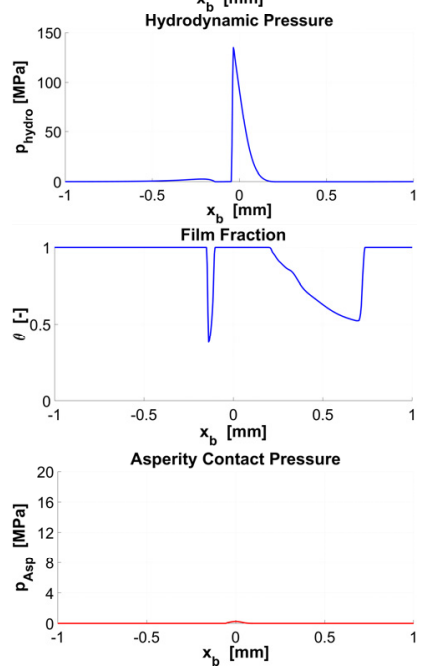

Figure 10 - Detailed plots showing the influence of the moving texture and PC model on the calculation of the hydrodynamic and asperity contact components of the total friction force for the textured slider surface with $80 \times 8 \times 1100 \mu \mathrm{m}$ pockets dimensions under mixed-lubrication regime (midstroke region, frequency: $3 \mathrm{~Hz}$, normal load: $70 \mathrm{~N}$, oil temperature $60^{\circ} \mathrm{C}$ ). Simulations performed (a) without and (b) with PC. 


\section{References}

[1] J. Anno, J. Walowit and C. Allen, "Microasperity Lubrication," Journal of Lubrication Technology, vol. 90, n², p. 351, 1968.

[2] S.-C. Vlădescu, A. Olver, I. Pegg and T. Reddyhoff, "The effects of surface texture in reciprocating contacts - An experimental study," Tribology International, vol. 82, pp. 28-42, 2015.

[3] H. Rahnejat, S. Balakrishnan, P. D. King and S. Howell-Smith, "In-Cylinder Friction Reduction Using a Surface Finish Optimization Technique," Proceedings of the Institution of Mechanical Engineers, Part D: Journal of Automobile Engineering, vol. 220, nº 9, pp. 1309-1318, 2006.

[4] L. Bertocchi, D. Dini, M. Giacopini, M. Fowell and A. Baldini, "Fluid film lubrication in the presence of cavitation: a mass-conserving two-dimensional formulation for compressible, piezoviscous and non-Newtonian fluids," Tribology International, vol. 67, pp. 61-71, 2013.

[5] T. Woloszynski, P. Podsiadlo and G. Stachowiak, "Efficient Solution to the Cavitation Problem in Hydrodynamic Lubrication," Tribology Letters, vol. 58, n 18, pp. 1-11, 2015.

[6] S. Medina, M. Fowell, S.-C. Vlădescu, T. Reddyhoff, I. Pegg, A. Olver and D. Dini, "Transient effects in lubricated textured bearings," Proceedings of the Institution of Mechanical Engineers, Part J: Journal of Engineering Tribology, vol. 229, nº 4, pp. 523-537, 2015.

[7] A. Almqvist, E. Essel, J. Fabricius and P. Wall, "Reiterated homogenization applied in hydrodynamic lubrication," Proceedings of the Institution of Mechanical Engineers, Part J: Journal of Engineering Tribology, vol. 222, nº 7, pp. 827-841, 2008.

[8] R. Ausas, P. Ragot, J. Leiva, M. Jai, G. Bayada and G. Buscaglia, "The Impact of the Cavitation Model in the Analysis of Microtextured Lubricated Journal Bearings," Journal of Tribology, vol. 129, no 4, pp. 868-875, 2007.

[9] H. Checo, R. Ausas, M. Jai, J.-P. Cadalen, F. Choukroun and G. Buscaglia, "Moving textures: Simulation of a ring sliding on a textured liner," Tribology International, vol. 72, pp. 131-142, 2014.

[10] E. Tomanik, F. Profito and D. Zachariadis, "Modelling the hydrodynamic support of cylinder bore and piston rings with laser textured surfaces," Tribology International, vol. 59, pp. 90-96, 2013.

[11] D. Gropper, L. Wang and T. J. Harvey, "Hydrodynamic lubrication of textured surfaces: A review of modeling techniques and key findings," Tribology International, vol. 94, pp. 509-529, 2016.

[12] L. Floberg, "Cavitation boundary conditions with regard to the number of streamers and tensile strength of the liquid," in In Cavitation and related phenomena in lubrication: proceedings of the 
1st Leeds-Lyon Symposium on Tribology, held in the Institute of Tribology, Department of Mechanical Engineering, University of Leeds, England, September 1974, 1974.

[13] H. Elrod and M. L. Adams, "A computer program for cavitation and starvation problems," em In Cavitation and related phenomena in lubrication: proceedings of the 1st Leeds-Lyon Symposium on Tribology, held in the Institute of Tribology, held in the Institute of Tribology, Department of Mechanical Engineering, University of Leeds, September 1974, Leeds, England, 1974.

[14] H. G. Elrod, “A cavitation and starvation algorithm,” Journal of Lubrication Technology, vol. 103, no. 3, pp. 350-354, 1981.

[15] F. Profito, M. Giacopini, D. Zachariadis and D. Dini, "A general finite volume method for the solution of the Reynolds lubrication equation with a mass-conserving cavitation model," Tribology Letters, vol. 60, no. 1, 2015.

[16] L. Galda, P. Pawlus and J. Sep, "Dimples shape and distribution effect on characteristics of Stribeck curve,” Tribology International, vol. 42, pp. 1505-1512, 2009.

[17] H. Zhang, D. Zhang, M. Hua, G. Dong and K. Chin, "A Study on the Tribological Behavior of Surface Texturing on Babbitt Alloy under Mixed or Starved Lubrication," Tribology Letters, vol. 56, pp. 305-315, 2014.

[18] X. Lu and M. Khonsari, “An Experimental Investigation of Dimple Effect on the Stribeck Curve of Journal Bearings,” Tribology Letters, vol. 27, pp. 169-176, 2007.

[19] M. Dobrica, M. Fillon, M. Pascovici and T. Cicone, "Optimizing surface texture for hydrodynamic lubricated contacts using a mass-conserving numerical approach," Proceedings of the Institution of Mechanical Engineers, Part J: Journal of Engineering Tribology, vol. 224, $\mathrm{n}^{\mathrm{o}}$ 8, pp. 737-750, 2010.

[20] C. Shen and M. Khonsari, "Effect of Dimple's Internal Structure on Hydrodynamic Lubrication," Tribology Letters, vol. 52, pp. 415-430, 2013.

[21] Y. Qiu and M. Khonsari, "Performance Analysis of Full-Film Textured Surfaces With Consideration of Roughness Effects," Journal of Tribology, vol. 133, pp. 021704-1, 2011.

[22] N. Patir and H. S. Cheng, "An average ow model for determining effects of three-dimensional roughness on partial hydrodynamic lubrication," Journal of Lubrication Technology, vol. 100, no. 1, pp. 12-17, 1978.

[23] N. Patir and H. S. Cheng, "Application of average flow model to lubrication between rough sliding surfaces," Journal of Lubrication Technology, vol. 101, no. 2, pp. 220-229, 1979.

[24] J. Greenwood and J. H. Tripp, “The contact of two nominally at rough surfaces," Proceedings of the Institution of Mechanical Engineers, vol. 185, n 1, pp. 625-633, 1970. 
[25] S.-C. Vlădescu, S. Medina, A. Olver, I. Pegg and T. Reddyhoff, "Lubricant film thickness and friction force measurements in a laser surface textured reciprocating line contact simulating the piston ring - Liner pairing," Tribology International, vol. (Forthcoming), 2016.

[26] S.-C. Vlădescu, S. Medina, A. Olver, I. Pegg and T. Reddyhoff, "The transient friction response of a laser textured, reciprocating contact to the entrainment of individual pockets," Tribology Letters, vol. (Forthcoming), 2016.

[27] F. Meng, Q. Wang, D. Hua and S. Liu, "A simple method to calculate contact factor used in average ow model," Journal of Tribology, vol. 132, no. 2, p. 024505, 2010.

[28] P. Wang, T. Keith Jr. and K. Vaidyanathan, "Combined surface roughness pattern and nonNewtonian effects on the performance of dynamically loaded journal bearings," Tribology Transactions, vol. 45, no. 1, pp. 1-10, 2002.

[29] F. Profito and D. Zachariadis, "Partitioned fluid-structure methods applied to the solution of elastohydrodynamic conformal contacts," Tribology International, vol. 81, pp. 321-332, 2015.

[30] F. Profito, D. Zachariadis and D. Dini, "Partitioned Fluid-Structure Interaction Techniques Applied to the Conformal EHL Solution of Dynamically Loaded Connecting-Rod Bearings," em 14th EDF/Pprime Workshop, Futuroscope - Influence of design and materials on journal and thrust bearing performance, Poitiers, France, 2015.

[31] R. Ausas, M. Jai and G. C. Buscaglia, "A mass-conserving algorithm for dynamical lubrication problems with cavitation," Journal of Tribology, vol. 131, no. 3, p. $031702,2009$.

[32] E. Tomanik, "Modelling of the asperity contact area on actual 3D surfaces," SAE Technical Paper, pp. 2005-01-1864, 2005.

[33] H. Checo, A. Jaramillo, R. Ausas and G. Buscaglia, "The lubrication approximation of the friction force for the simulation of measured surfaces," Tribology International, pp. 390-399, 2016.

[34] G. Carbone and F. Bottiglione, "Asperity contact theories: Do they predict linearity between contact area and load?," Journal of the Mechanics and Physics of Solids, vol. 56, pp. 2555-2572, 2008 .

[35] M. Ciavarella, V. Delfine and G. Demelio, "A "re-vitalized" Greenwood and Williamson model of elastic contact between fractal surfaces," Journal of the Mechanics and Physics of Solids, vol. 54, pp. 2569-2591, 2006.

[36] M. Ciavarella, J. Greenwood and M. Paggi, "Inclusion of "interaction" in the Greenwood and Williamson contact theory," Wear, vol. 265, pp. 729-734, 2008. 


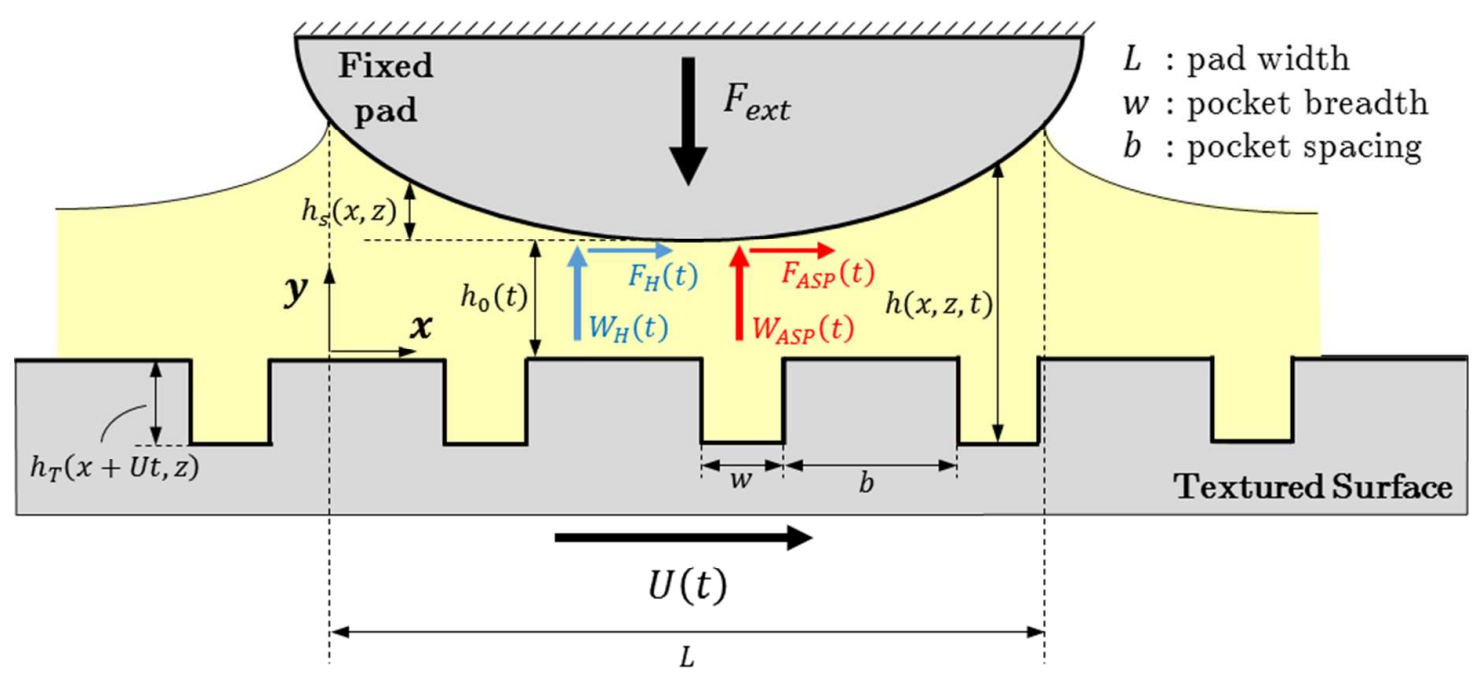

Figure 1 - Schematic view of the piston ring/cylinder liner contact system with moving texture. Notice that the fluid flow problem is described with respect to the fixed pad (piston ring) reference system. 


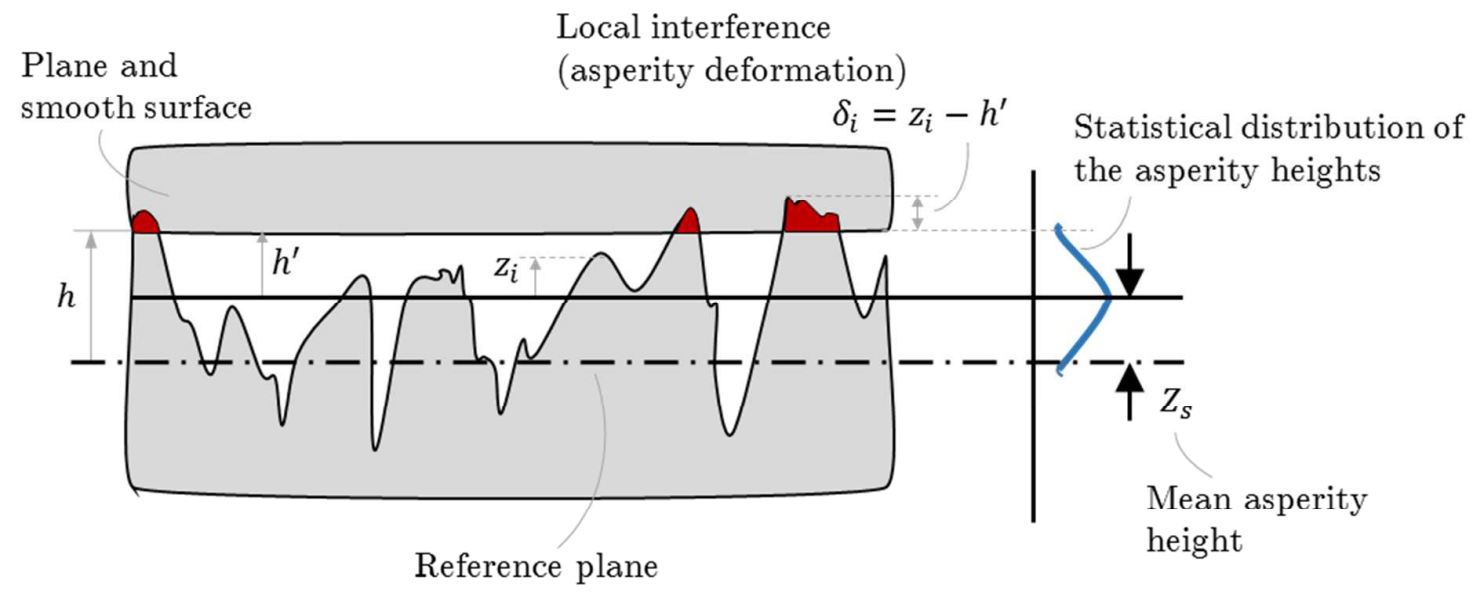

Figure 1 - Contact between a rigid, smooth plane against a rough surface illustrating the main variables of the Greenwood-Tripp model for rough contact. 


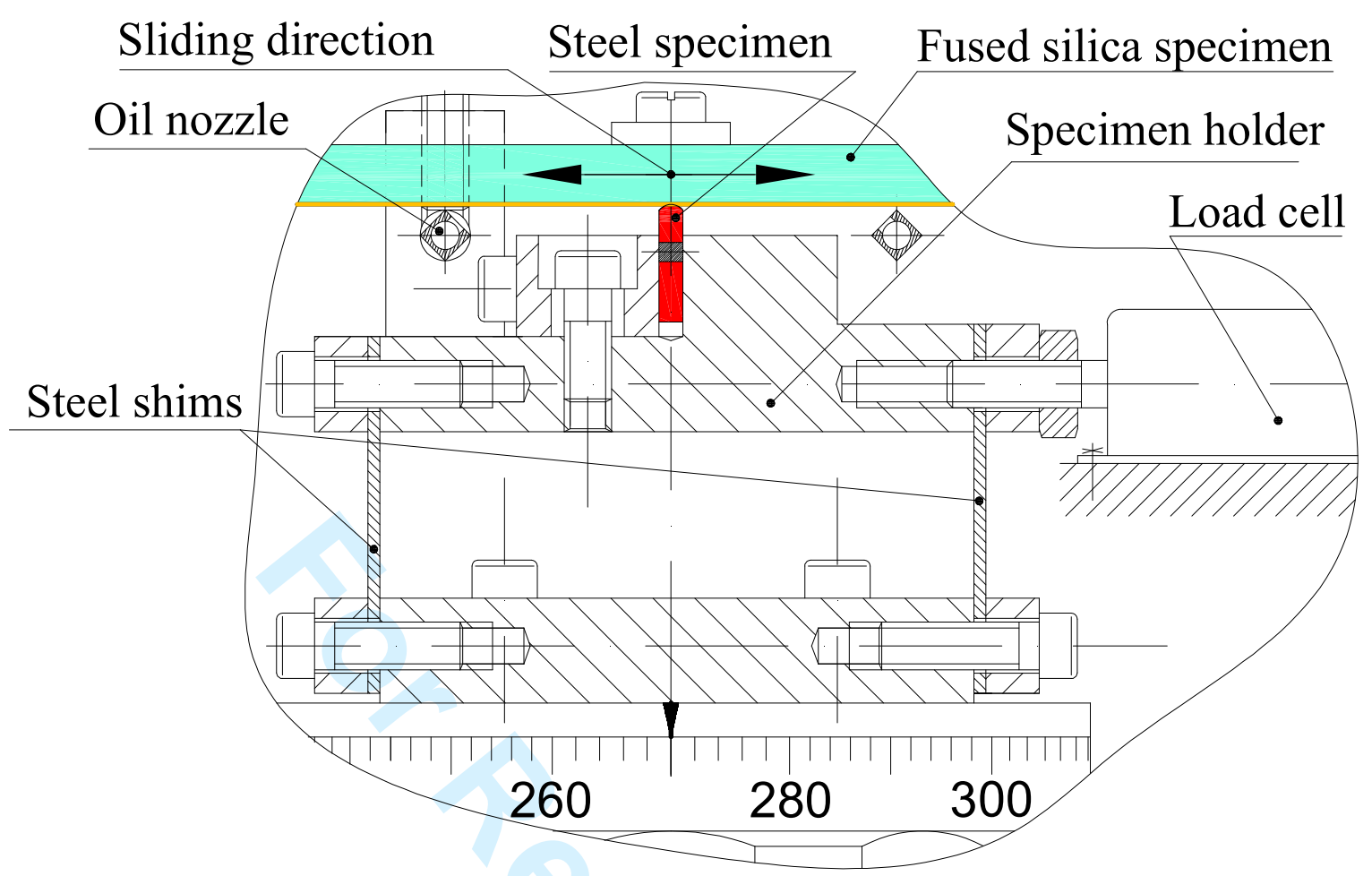

Figure 1 - Schematic representation of the in-house developed experimental set-up. 
Figure 1 - Three dimensional surface plot of the laser surface textured fused silica specimen with pocket breadth $80 \mu \mathrm{m}$. 


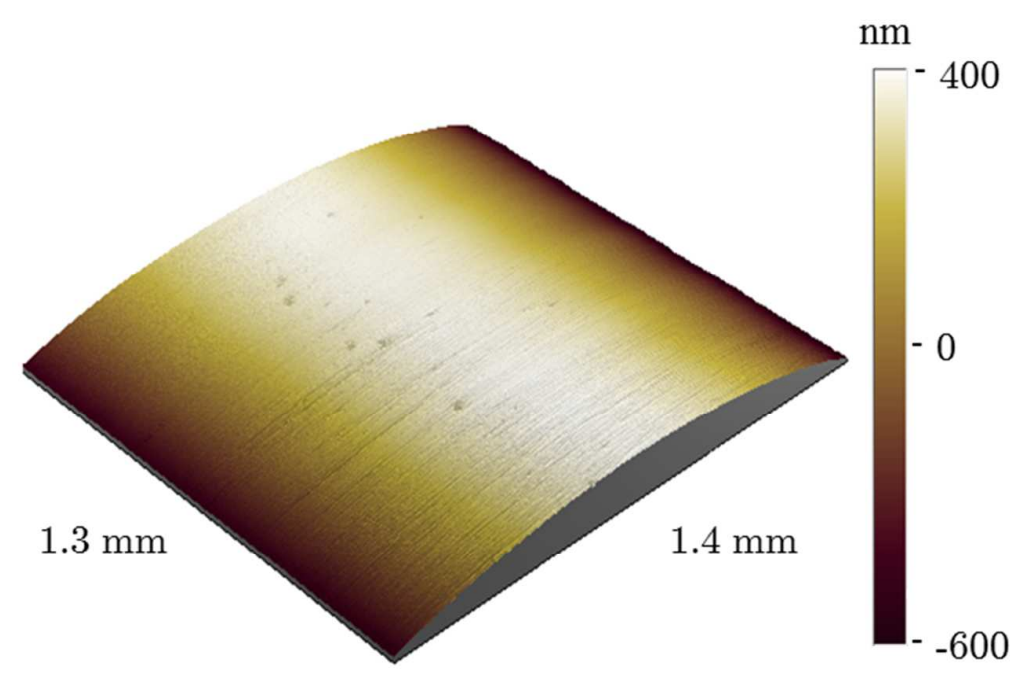

Figure 1 - Three dimensional surface topography of the barrel-shaped steel specimen as obtained by the Veeco Wyko optical profiler. 

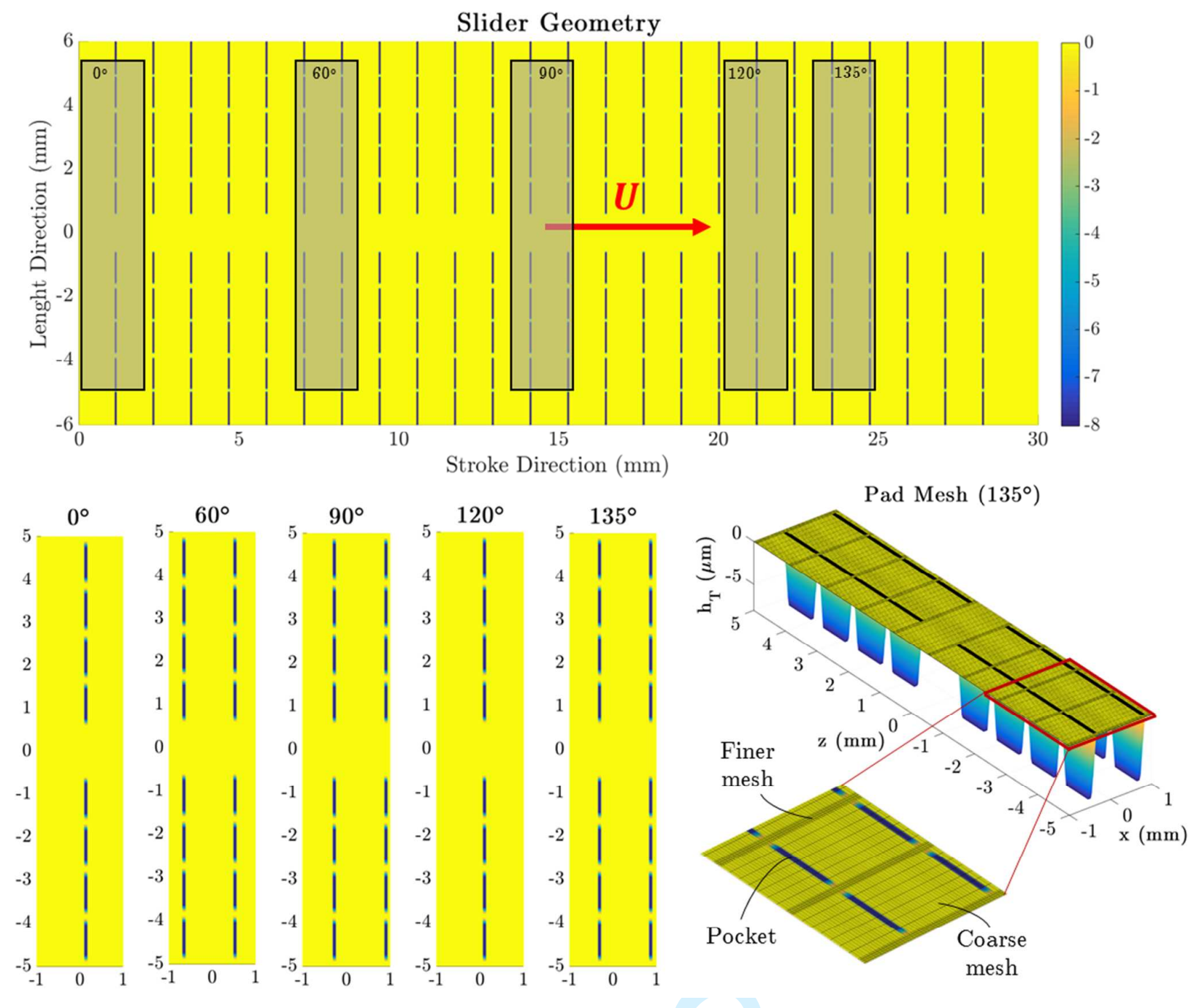

Figure 1 - Entire geometry of the textured slider and representative "instantaneous" geometries projected on the pad mesh for the $0^{\circ}, 60^{\circ}, 90^{\circ}, 120^{\circ}$ and $135^{\circ}$ stroke positions. 
Experimental Results: Untextured vs. Textured Slider

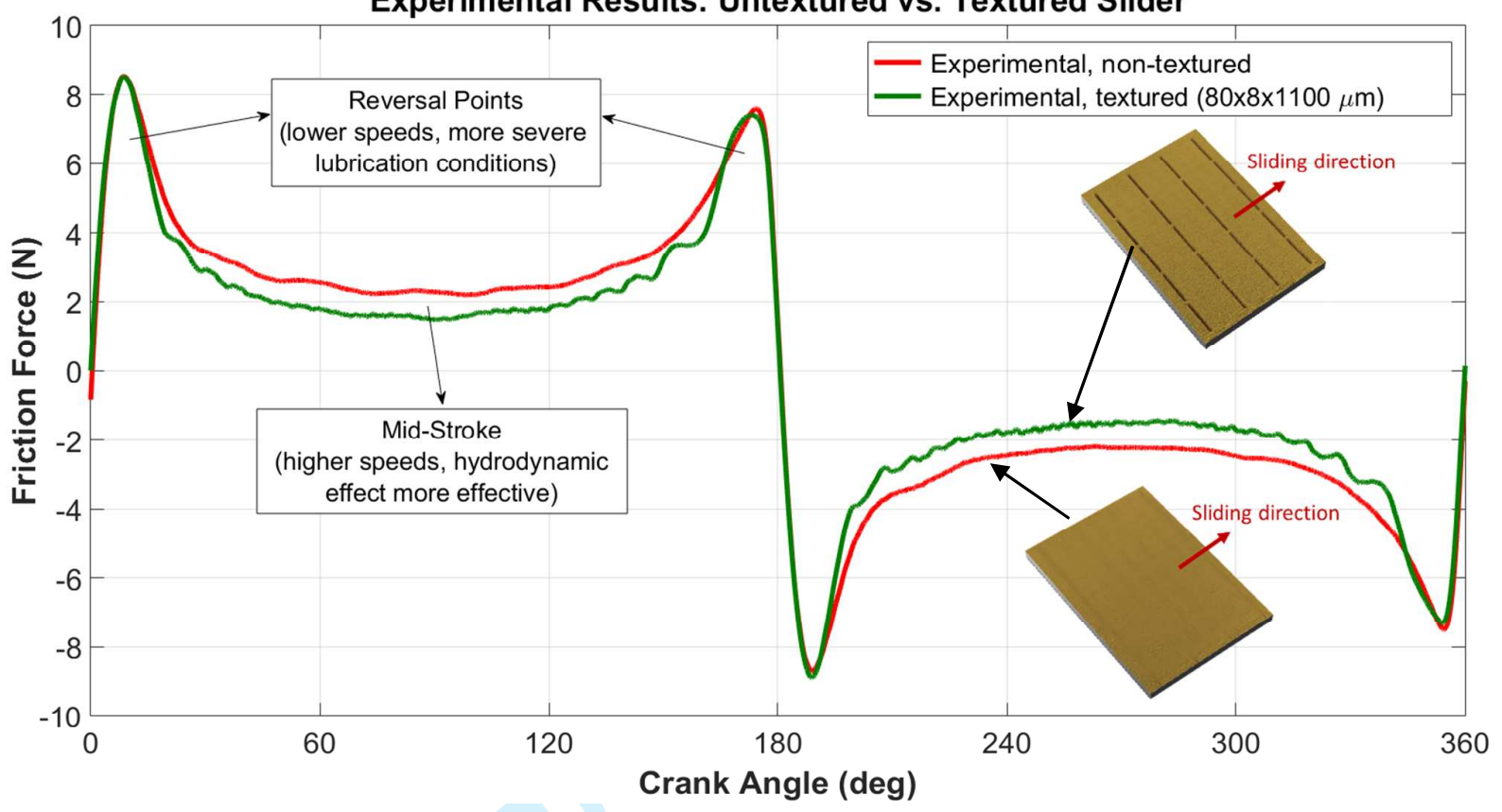

Figure 1 - Friction force comparison between non-textured and textured slider surfaces under mixed-lubrication regime (frequency: $3 \mathrm{~Hz}$, normal load: $70 \mathrm{~N}$, oil temperature $60^{\circ} \mathrm{C}$ ). 
Figure 1 - Comparison between experimental and simulation results for the non-textured slider surface under mixed-lubrication regime (frequency: $3 \mathrm{~Hz}$, normal load: $70 \mathrm{~N}$, oil temperature $60^{\circ} \mathrm{C}$ ). 


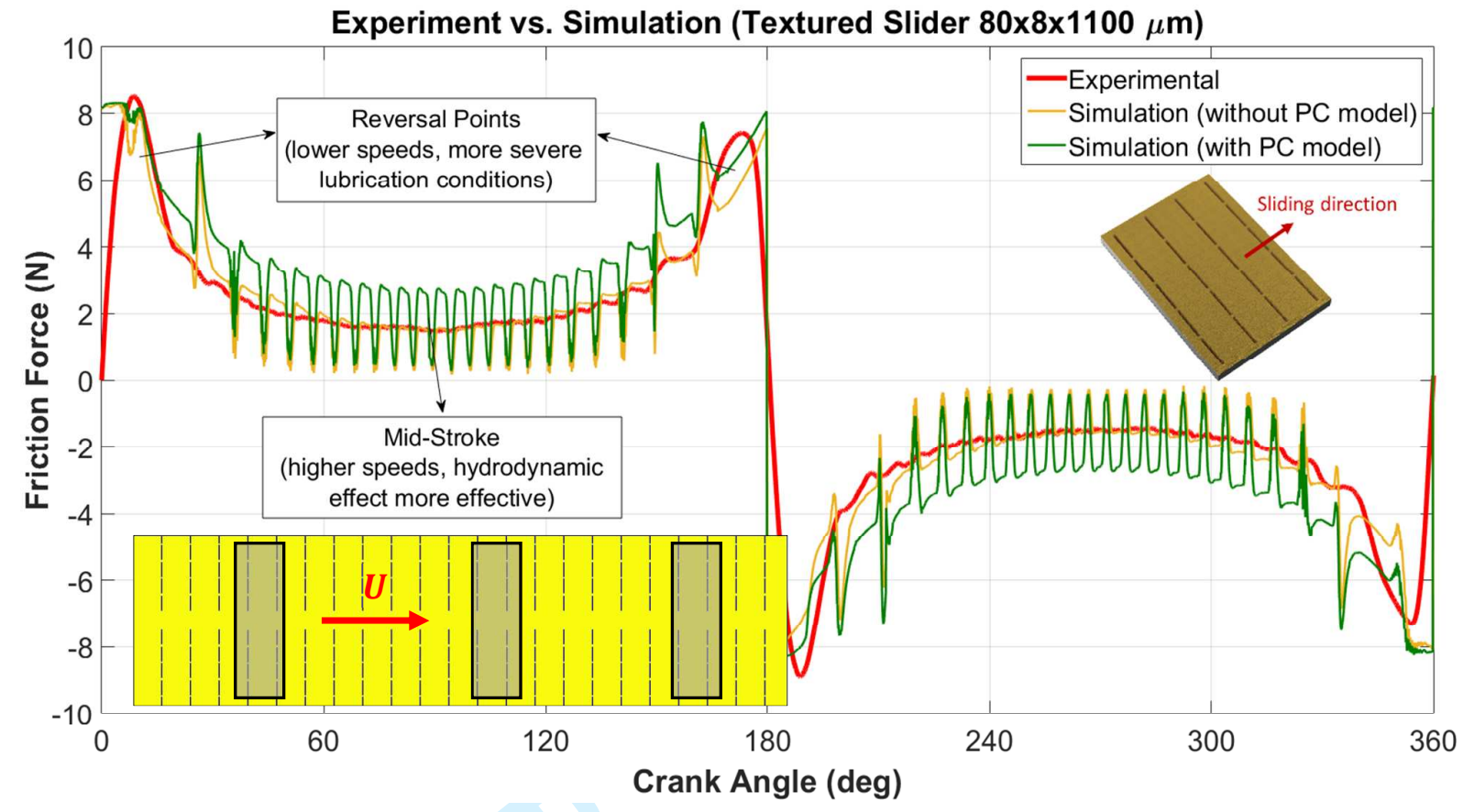

Figure 1 - Comparison between experimental and simulation results for the textured slider surface with $80 \times 8 \times 1100 \mu \mathrm{m}$ pockets dimensions under mixed-lubrication regime (frequency: $3 \mathrm{~Hz}$, normal load: $70 \mathrm{~N}$, oil temperature $60^{\circ} \mathrm{C}$ ). 

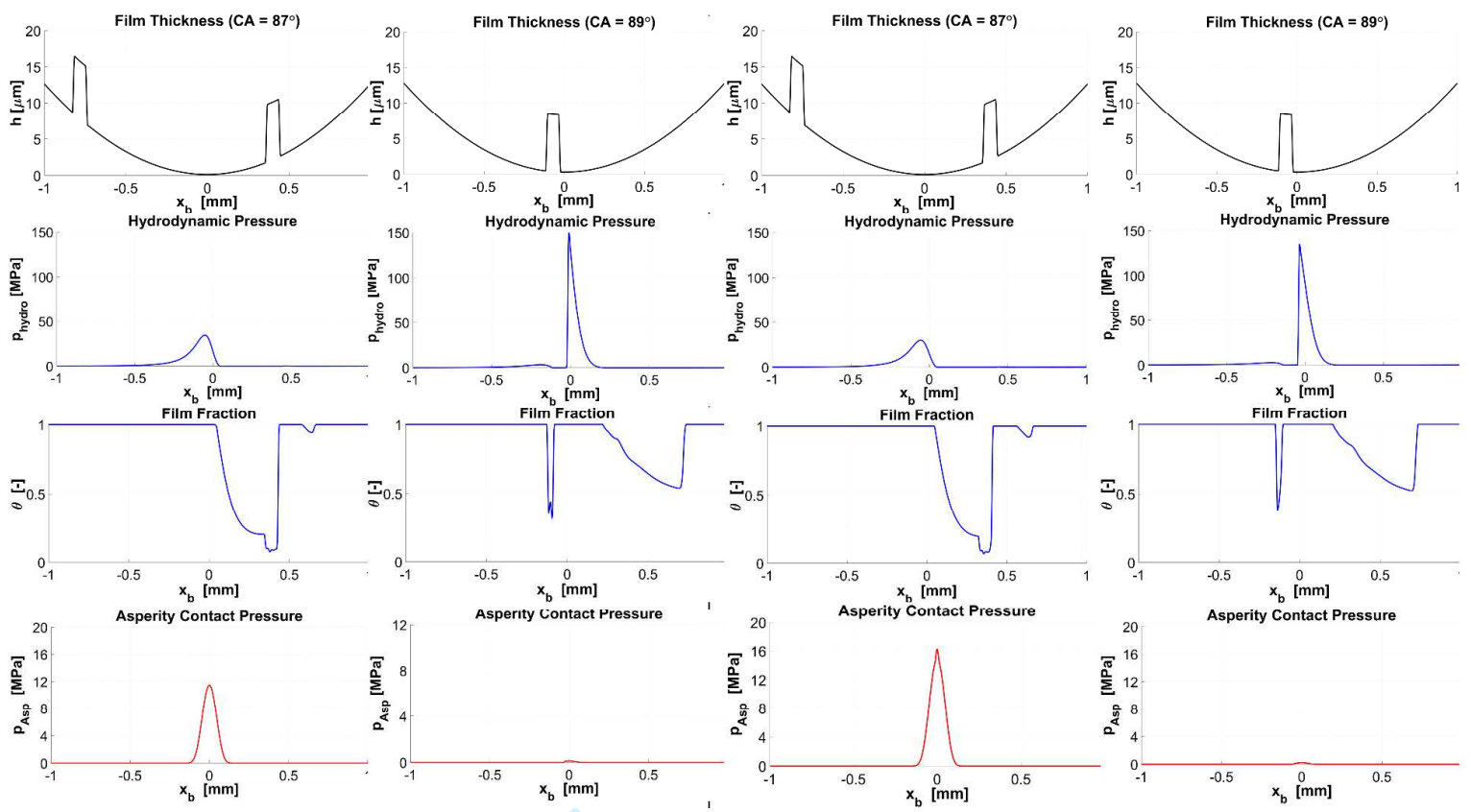

(a)

(b)

Figure 1 - Detailed plots showing the influence of the moving texture and PC model on the calculation of the hydrodynamic and asperity contact components of the total friction force for the textured slider surface with $80 \times 8 \times 1100 \mu \mathrm{m}$ pockets dimensions under mixedlubrication regime (mid-stroke region, frequency: $3 \mathrm{~Hz}$, normal load: $70 \mathrm{~N}$, oil temperature $60^{\circ} \mathrm{C}$ ). Simulations performed (a) without and (b) with PC. 
Table 1 - Input parameters for the reciprocating test simulations.

\begin{tabular}{|c|c|c|c|}
\hline \multirow[b]{2}{*}{ Parameter } & \multicolumn{2}{|c|}{ Values } & \multirow[b]{2}{*}{ Unit } \\
\hline & $\begin{array}{c}\text { Slider } \\
\text { (fused silica) }\end{array}$ & $\begin{array}{c}\text { Pad } \\
\text { (AISI 52100 steel) }\end{array}$ & \\
\hline$E$ & 72.7 & 210 & $\overline{\mathrm{GPa}}$ \\
\hline$v$ & 0.17 & 0.30 & - \\
\hline$H$ & 1000 & 850 & $\mathrm{HV}$ \\
\hline$S a$ & 0.068 & 0.088 & $\mu \mathrm{m}$ \\
\hline$S q$ & 0.085 & 0.102 & $\mu \mathrm{m}$ \\
\hline$Z_{S}$ & 0.11 & 0.10 & $\mu \mathrm{m}$ \\
\hline$\sigma_{S}$ & 0.06 & 0.07 & $\mu \mathrm{m}$ \\
\hline$\beta_{S}$ & 5.81 & 4.84 & $\mu \mathrm{m}$ \\
\hline$\eta_{S}$ & $6.01 \times 10^{10}$ & $4.64 \times 10^{10}$ & $\mathrm{~m}^{-2}$ \\
\hline$\gamma$ & 1 & 9 & - \\
\hline$\mu_{B L}$ & \multicolumn{2}{|c|}{0.12} & - \\
\hline \multicolumn{4}{|c|}{ Test Conditions } \\
\hline Stroke & \multicolumn{2}{|c|}{28.6} & $\overline{\mathrm{mm}}$ \\
\hline Frequency & \multicolumn{2}{|c|}{3} & $\mathrm{~Hz}$ \\
\hline Load & \multicolumn{2}{|c|}{70} & $\mathrm{~N}$ \\
\hline \multicolumn{4}{|c|}{ Lubricant Properties } \\
\hline Temperature & \multicolumn{2}{|c|}{60} & ${ }^{\circ} \mathrm{C}$ \\
\hline Viscosity & \multicolumn{2}{|c|}{35.09} & $\mathrm{mPa} . \mathrm{s}$ \\
\hline Density & \multicolumn{2}{|c|}{841} & $\mathrm{~kg} / \mathrm{m}^{3}$ \\
\hline
\end{tabular}

